\title{
Sensory Evaluation in Determining Acceptability of Scrub Cream: Sumenep Kingdom's Body Scrub Modifications
}

\author{
Octaverina Kecvara Pritasari \\ Department of Home Economis \\ Universitas Negeri Surabaya \\ Surabaya, Indonesia \\ octaverinakecvara@unesa.ac.id
}

\author{
Mangestuti Agil ${ }^{\mathrm{a}}$, Widji Soeratri ${ }^{\mathrm{b}}$, \\ ${ }^{a}$ Department Botany Pharmacy \\ Pharmacognocy \\ ${ }^{\mathrm{b}}$ Department of Pharmaceutical \\ Universitas Airlangga \\ Surabaya, Indonesia \\ mmangestuti@airlangga.ac.id
}

\begin{abstract}
The main purpose of this study is to see the acceptance of modified creams from traditional scrubs of Sumenep Kingdom (one of big Kingdom in Madura, Indonesia). The use of three basic scrub creams are derived from the previous studies, namely: viyoch, the basic modification by using anionic acid aromatic stearate acid, basic stelmakiene scrub modified with aromatic stearate acid anionic surfactant, and basic modification substance by using anionic sodium lauryl sulfate. The solid Sumenep Kingdom cream is diluted as a control. This study measures the acceptance of three availability types of modified Sumenep ant brush. There are 300 students as populations, and 50 students as samples. The product had been tested to 50 respondents, also given questionnaires through assessment criteria based on the indicator of feeling (smoothness), ease of use (form, performance), and preferences (smell, color). Data were analyzed by chi-square test and Friedman test. The results showed that the indicator of smoothness, shape, and effect of performance on acceptability of Sumenep Kingdom scrub cream and body scrub with a LIKE base modified with anionic sodium lauryl sulfate is the most widely accepted.
\end{abstract}

\section{Keywords—BodyScrub; Acceptability; Sumenep Kingdom}

\section{INTRODUCTION}

The concept of beauty and cosmetics comes from early humans and civilizations. Generally, herbal cosmetics are also referred to as natural cosmetics. WHO demonstrates that for about $80 \%$ of world population relies on natural products for their health care, because of other medicine's effects inflicted and rising cost of the modern medicine [1] The use of plants as a source of food, healing, and body care has a wide range. It is said that the biological richness and diversity of Indonesia is a source of medicine and cosmetics [2]. At present cosmetics industry is focusing on launching organic cosmetic products because people are now becoming more and more conscious about the chemicals and their harmful effects in the cosmetics [3]. Body and skin care have different practices, production, use, and cosmetic names. Different methods of body care at each location create different terms. Body care method for women in Java is known as "luluran" (rubbing the skin). This type of body care is widely used by princesses in the kingdom. The skin after exfoliation becomes smooth, soft, moisturized, but also less resistant to the effects of external mechanical [4]. In Madura, the method of "luluran" is also done by the Madurese who are influenced by the culture of the Kingdom of Sumenep [5].

Interview results in pre-research studies of scrub producers show that scrubs used in Sumenep were developed earlier by the princesses of Sumenep Kingdom. Therefore, it is named Sumenep Kingdom scrub. Unfortunately, there is no written document on its scrub formulas while it had been studied and used empirically since many years ago. The way of using the scrubs is simple. First, blend the scrub (granule form), add water, then rub it into the skin and let it dry. Rescrub and wash it by using fresh water. This method takes time and often leaves the yellow dots on the skin which makes it less practical. Therefore, Madurese women begin to leave the brush body of Sumenep Kingdom and change it into cream. Based on this fact, extracting the dry powder plant and mix it with development is done on the change of traditional body brush form into cream form. The new variation in the form of modified body scrub is expected to improve the acceptance of Sumenep scrubs for the users, in addition to the excellence of the Royal Sumenep cream.

The method of evaluating granule form changes into cream form of existing products, differential testing is one of the most commonly used sensory techniques [6]. The availability of these creams was produced into three different types of $\mathrm{O} / \mathrm{W}$ types. The basic $\mathrm{O} / \mathrm{W}$ types in this study used the basic formula of cleaning cream, from previous research results. The goal is to obtain the most suitable form of cream as the base of scrub. This study used three basic available cream scrubs taken from previous studies: 1) Viyoch base modified by using aromatic stearate acid anionic surfactant, 2) basic availability of modified stelmakiene cream scrubs using anionic aromatic stearate acid. -TEA, and the base of LIKE availability modified using anionic sodium sulfate. The solid Sumenep Kingdom cream is diluted as a control.

\section{METHODS}

This is a research and developmental design. There were 300 population and 50 samples. Before giving treatment to the respondents, they took the sensory test by filling the 
questionnaire sheets. The sensory test was done because the cosmetic composition can modify the sensory attributes and influence the consumer acceptance ${ }^{7}$. The combination of substances influences the initial feel, how the formulation spreads on the skin, whether and how fast it is absorbed and how the skin feels after the use. Each respondent filled out the informed consent sheet provided. Given that social experiment involving humans, Van De Poel suggests deontological restrictions of informed consent. This restriction requires that experiments using human subjects are morally acceptable if the subject had voluntarily agreed to take part and be based on his or her own judgment without coercion[8]. There are 4 kinds of body scrub cream applied on samples. They are Sumenep Kingdom scrub and three kinds of modified Sumenep Kingdom body scrub cream. There are two (2) stages on this research, the first stage is preparing modified Sumenep Kingdom body scrub cream. It was devided into some ways : 1. Making rice starch flour: The rice which had been measured is washed and soaked until it is soft. Then, filter the rice and let it dry to make sure no water content remaining. After that, the rice is blended into flour. Then, the soft rice flour is dried in the oven to lose its water content. Finally, the dried rice flour is sieved to get a good quality of flour, 2. Making Spice Powder: the turmeric, temugiring, and lime skin, fennel, pulosari (Alyxia stellata) are measured and Simplicia, the mixed materials, is dried by using oven. After that, this simplicia is sublimated. Finally, simplicia is sieved to get a soft powder. The second stage is making Traditional Sumenep Kingdom Scrub. Based on the previous research, the Sumenep Kingdom scrub cream is made into three kinds[7]. The scrub cream is $\mathrm{O} / \mathrm{W}$ typed cleansing cream base of modified Viyoch that uses the anionic surfactant stearic acid-TEA, O/W typed cleansing cream base of modified stelmakiene scrub cream availability uses the anionic surfactant stearic acid-TEA, O/W typed cleansing cream base of modified Like uses anionic sodium lauryl sulfate. The control is traditional Sumenep Kingdom scrub in the form of Granule.

The materials used to make modified Sumenep Kingdom body scrub cream are : Glycerilmonostearate, mineral, oil, cetyl alcohol, stearyl alcohol, stearat acit, petrolatum, yellow beeswax, isopropyl miristat, hidroxi toluene, trietanolmin, nipgin, and nipasol.The equipment are used to make modified Sumenep Kingdom body scrub cream in the form of Granule are; alun, lumping, pipisan, and strainer. While in making scrub cream, it needs: tools to measure cream and tools to test physical stability. To measure cream, it is used: glasses, analic weight (Sartorius type BP 2215), ceramic bowl, waterbath, hummer, and stamper. Tools to test physical stability are viscometer Rion viscotester VT-04E, Rion Co.Ltd Jepan, spindle no.1/2 and $\mathrm{pH}$ meter (schott).

The test of traditional Sumenep Kingdom scrub was conducted by using traditional method, namely applying scrub cream on the arm. The number of scrub cream applied on hand is $\pm 1,7 \mathrm{mg} / \mathrm{cm}^{2}[9]$. The body scrub cream was massaged in a circular motion by finger, and then sensory test was done by feeling indicator (smoothness), that is, feeling where cream contains particle while applying and scrubbing skin. The form of indicator is observing and touching on the viscosity of body scrub cream, showed the consistency of scrub cream. Performance indicator, sticky impression and the ease of body scrubs felt when it was applied to the skin and washed. The smell detected by smelling aroma of cream body scrub cream when it is applied to the skin. Color recognized by observing the brownish on the body scrub cream when it is applied on the skin.

Filling the questionnaire by the respondents was conducted after they filled forms of; informed consent, respondents' agreement, and also after applying the scrub cream on the back of arm. After that, the respondents filled the form by crossing the choices, using the likert scale (1. very disagree; 2 . disagree; 3 . moderately agree; 4 . Agree, 5. Very agree) on the questions in the form. The scrub cream was applied to the respondents to find out its acceptability.

\section{A. Statistical Data Processing}

The reliability test uses Cronbbach' alpha technique (alpha questionnaire). Data is analyzed by using Chi square to find out the influence of each indicator on scrub cream acceptability. Then, Friedman test is used to find out the most accepted scrub cream by respondent.

\section{RESULTS AND DISCUSSION}

\section{A. Results}

The Observation of The Sumenep Kingdom Scrub Cream Acceptability was such as on figure 1.

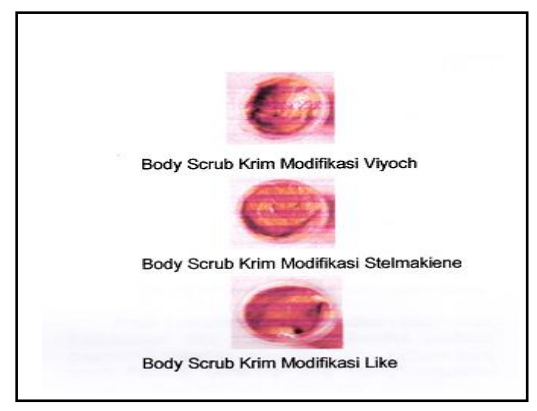

Fig.1 Body Scrub Cream Modification

Chi square test was conducted on three kinds of modified Sumenep Kingdom body scrub cream to know whether indicators of smoothness, form, performance, smell, and color influence the acceptability of respondents on body scrub. $\mathrm{X}_{1}{ }^{2}$ Chi Square ${ }_{\text {observed }}=4.574$ is less than Chi square $\mathrm{X}_{\text {table } 0,005(3)}^{2}=7.815$ with $\beta$ probability of 0.206 (greater than 0.05 ). The score means that the impression of smoothness or roughness on the scrub particle felt while applying body scrub does not influence the acceptability of respondent on choosing body scrub. Chi square test results on three kinds of body scrub cream and control shows that $\mathrm{X}^{2}$ Chi Square observed $=9.680$ is greater than Chi square $X^{2}$ table 0,005(3) with $\beta$ probability of 0.013 (greater than 0.05). This shows that viscosity of cream influences the respondents' acceptability in choosing body scrub. Chi square test on the three kinds of body scrub cream and control shows that Chi Square $\mathrm{X}_{1}^{2}$ observed $=39.362$ is more than Chi square $\mathrm{X}^{2}$ table $0,005(3)=$ 
7.815 with $\beta$ probability of 0.000 (less than 0.05 ) that means that the sticky impression and ease of scrub cream and wash while applying the scrub on skin influence respondents' acceptability on choosing the body scrub. Chi square test on the three kinds of body scrub cream and control in the form of Granule (X4) showed that $\mathrm{X}_{1}^{2}$ Chi Square ${ }_{\text {observed }}=19.093$ is higher than Chi square $\mathrm{X}^{2}$ table $0,005(3)=7.815$ with $\beta$ probability of 0.000 (less than 0.05 ) that means $\mathrm{Ho}_{1}$ is accepted so that smelling the aroma while applying cream on skin influences respondents' acceptability in choosing the body scrub is received. Chi square test on the three kinds of body scrub cream and control in the form of solid material shows that $\mathrm{X}_{1}^{2}$ Chi Square observed $=18.711$ is greater than $C h i$ square $\mathrm{X}^{2}$ table $0,005(3)=7.815$ with $\beta$ probability of 0.000 (less than 0.05 ) that means the color of body scrub can influence respondents' acceptability in choosing the body scrub.

Friedman test result of Sumenep Kingdom scrub cream as such as on table 1 .

TABLE 1 FOUND THAT THE MODIFIED SUMENEP KINGDOM

\begin{tabular}{|c|c|c|c|}
\hline Indicators & $\begin{array}{c}\text { Mean rank } \\
\text { of Viyoch } \\
\text { Modification }\end{array}$ & $\begin{array}{c}\text { Mean rank of } \\
\text { Stelmkiene } \\
\text { Modification }\end{array}$ & $\begin{array}{c}\text { Mean rank of } \\
\text { Like } \\
\text { Modification }\end{array}$ \\
\hline Smoothness & 2.66 & 2.31 & 2.51 \\
\hline From & 2.27 & 2.44 & 2.51 \\
\hline Performance & 2.42 & 1.86 & 2.68 \\
\hline Smell & 2.29 & 2.40 & 2.50 \\
\hline Color & 2.33 & 2.37 & 2.40 \\
\hline
\end{tabular}

. Then, by using smoothness indicator, the respondents choose modified Viyoch scrub cream as the most acceptable one. From indicator of form, based on the mean rank data, shows that respondents' scoring on viscosity of three Sumenep Kingdom body scrubs which most accepted is modified like body scrub. From indicator of performance, mean rank score shows that the most accepted Sumenep Kingdom body scrubs is modified like body scrub. Form indicator of smell, the mean rank score shows that the aroma of modified like body scrub is the most acceptable. While, based the mean rank score of the indicator of color, the respondents choose modified like body scrub cream as the most accepted body scrub because it has the similar color with traditional Sumenep Kingdom scrub in the form of Granule.

\section{B. Discussion}

As known from the Chi-square test, the smoothness of body scrub does not have the significant influence on respondents' acceptability in choosing a certain body scrub. However, the three body scrubs used in this research are potentially accepted with body scrub cream by the market. Based on the observation, there is different perception of its smoothness because the different form and size of scrub's particle influences the respondents' perception while applying the three body scrubs on the skin. Therefore, they think that cream is more easily used [10]. As a comparison, the particle size of body scrub product in the market has a diameter of between $\pm 30-300 \mathrm{Cm}$. Based on observations with 2000x magnification using a scanning electron microscope typed fei inspect S50 in material and Metallurgy laboratory in Institute of Sepuluh November on the three modified body scrubs, it was found that the particle size of scrub cream in this research has range of 3.746-5.278 $\mathrm{Im}$ for modified Viyoch scrub cream, 2.914-6.669 $9 \mathrm{~m}$ for modified Stelmakiene scrub cream, and, $3.503-5.801 \mathrm{Im} \mathrm{,} \mathrm{modified}$ like scrub cream. This indicates that particle size of three scrub cream has the similar range of particle size of the same product sold commercially in the market or accepted by the scrub consumers.

The particle form of modified Viyoch body scrub in the picture looks flat. The formula of basic cleansing cream of modified Viyoch using the anionic surfactant stearic acidTEA may be able to dissolve active material such as simplicia. While, the respondents assessed that The Stelmakiene scrub cream is not accepted, because the particle in this scrub has combination of various forms, round and spire. These various forms are not found in Viyoch scrub cream and modified like body scrub, which means that the basic cleansing cream of modified stelmakiene using the anionic surfactant stearic acid-TEA does not dissolve simplicia.

Table I. The form indicator of the three body scrubs shows that cream viscosity influences respondents' acceptability on choosing body scrub. The respondents think that influence of viscosity on the acceptability of scrub cream has dense consistence. The dense consistence of this body scrub thought that it influences joyful impression while using, because the scrub cream with big particle, hard, spire in the media has the low viscosity that will produce the hard texture and sandy that impacts to user's impression which is compared to small particle, soft, and smooth in media which has high viscosity[11]. Based on mean rank data, the modified body scrub which has the highest acceptability is modified Like, this basic cream has the dense consistence and easily dissolve the scrub. Therefore, the respondents feel the dense cream and soft particle within. Furthermore, to know whether the three body scrub used in this research have opportunity to be accepted by the consumers entirely so that measurement is done to compare this product to other five different branded body scrubs which have been exist in the market and about three up to five brands have their own wide market in Indonesia.

From those five different branded body scrubs, the average score of cream viscosity are $80-480 \mathrm{dPas}$, while the average score of body scrub viscosity used in this research $225 \pm 5.48 \mathrm{dPas}$ for modified Viyoch body scrub, 181.67 \pm 7.53 dPas for modified Stemakiene body scrub cream, and $233.33 \pm 5.16$ for modified like scrub cream. Therefore, the scrub cream used in this research is still included in the range of scrub cream viscosity wanted by the entire consumers. It means that the modified Viyoch and modified like scrub cream are potentially accepted. 
Based the performance indicator, the modified Like body scrub is the most accepted one because this cream is less sticky, where its stickiness relates to the usage of basic body scrub of modified like containing surfactant sodium laurel sulfate, so that it is easy to wash [12]. cream was O/W type emulsion, hence can be easily washed with plane water that gives better customer compliance[13]. While, basic body scrub cream of modified Viyoch and modified Stelmakiene have the same surfactant, the stearic acid-TEA.

Based on smell indicator, the result of Chi square test shows that Simplicia aroma of body scrub cream applied on skin influences respondents' acceptability on choosing the body scrub. This influence is caused by the use of aromatic simplicity in this study which can give pleasant effects or make the user happy. In addition, Culture has a profound influence on all aspects of human behavior[14]. Aromatherapy is a cultural heritage since ancient times. The use of aromatherapy derived from spices in cosmetics is highly preferred. Therefore, the cream with the highest acceptability is a cream that has aromatherapy aroma that makes a joyful effect. From the average rating of all body scrub cream modifications, it was found that modified as body scrub cream was the most widely accepted. It is assumed that the basic scrub cream interacts with the active ingredients, such as spices, thus affecting the scent of scrub cream and the respondent's perception on the scent level on the scrum cream is subjective.

Based on color indicator, the result of Chi square test shows Sumenep Kingdom scrub cream influences the respondents' acceptability on choosing certain body scrub. The color expected in this scrub cream is tawny as seen in the control variable. The color of basic body scrub cream of modified Viyoch is white, modified Stelmakiene body scrub cream is merely yellow, and modified like body scrub cream is yellowish. It is assumed that there is interaction between basic scrub and active material so it influences the color change of Sumenep Kingdom scrub cream. Selection of appropriate colorant for a specific pharmaceutical dosage form plays an important role in manufacturing of the pharmaceutical dosage forms, because the elegance and eye appeal of a colored product is valuable[15]. Although, the number of Simplicia percentage added in the three body scrub cream formula is the same, the modified like body scrub has the similar color with traditional scrub cream.

According to the deviation standard diagram, it is found that each scrub cream has no significant difference, which means that among scrub cream of modified Viyoch, Modified Stelmakiene and Modified Like using surfactant, anionic sodium lauryl sulfate have the same opportunity to be accepted by scrub consumers like solid scrub $\mathrm{x} 4$.

\section{CONCLUSION}

Based on the deviation standard of all acceptability score indicators of all uses on each scrub cream, it is found that each scrub cream has no significant different, which means that among scrub cream of modified Viyoch, Modified
Stelmakiene and Modified Like have the same opportunity to be accepted. Therefore, it can be concluded that feeling (smoothness) wanted by all respondents, the smoothness of scrub particle influences the respondents' acceptability on choosing certain scrub cream, and modified Viyoch scrub cream has the highest acceptability among others. Ease of use (form) indicator, where the cream viscosity influences respondents' acceptability in choosing certain scrub cream, and scrub viscosity which has the highest acceptability among others is modified like scrub cream. Ease of use (performance), where the criteria of scrub cream's stickiness and ease of wash influence respondents' acceptability in choosing certain scrub cream. The modified like scrub cream is the most accepted among others. Preference (smell) indicator, the aroma applied on the skin influences respondents' acceptability in choosing certain scrub cream. The cream aroma with the highest acceptability is modified like scrub cream according to the consumers. The preference indicator (color), the color of Sumenep Kingdom scrub cream influence respondents on choosing certain scrub cream and the color of cream with the highest acceptability is modified like scrub cream.

\section{ACKNOWLEDGMENT}

We thank to many informants who kindly assisted us in this study, particularly to the royal family of Sumenep Kingdom, who share their local ethno-botany knowledge and special thanks for all make up department students of State University of Surabaya for the valuable assist.

\section{REFERENCES}

[1]. Laxmi s Joshi,hashal a pawar, 2015. Herbal cosmetics and cosmecurticals : An Overview, Natural Product Chemistry And Research, Vol 3. Issue 2 . doi:10.4172/2329-6836.1000170

[2]. Tilaar Martha, 2010. The green Science Of Jamu : Pendekatan Pragmatik untuk kecantikan dan Kesehatan, Dian Harapan, Jakarta.

[3] Kapoor Mansi, Si Suman, 2014. "Strategic Analysis of Cosmeceuticals with Special Reference To Antiaging Creams, International Journal Of Business And Management Invention ISSN (online)", pp 2319-8028, Issn Print : 2319-801X. Volume 3Issue 1\| January. 2014\| PP.52

[4] Sulek M.W, Zieba M, Mazurek N., "Quality Estimation of Hand Cream With Oxyteylated ilicone And Oxylated Lanolin Mixture", Polish Journal Of Comodity Science, Vol. 4. Issue 29. 2011, pp 41-51

[5]Saptandari Pinky, 2012. "Sistem Kebugaran Tradisional Indonesia Dalam Kajian Budaya". Proceding The $4^{\text {th }}$ International Conference On Indonesian Studies : Unity, Diversity and Future, Fakultas Ilmu Pengetahuan Budaya Universitas Indonesia, pp.634

[6]Gisele Mara Silva Goncalves, Silvana Mariana Srebernich, Bartira Guicardi vercelino. And Bruna Meli Zampieri, 2013. Influence Of The Presence And Type Of Fragrance On The Sensory Perception Of Cosmetics Formulations. Brazilian Archieves Of Biology And Technology An Iternational Journal Vol. 56.n2.pp.203-212, march-april 2013 ISSN 1516-8913

[7]Jacobs F. J, Van De Poel ibo, Osseweijer, P., 2011. Sunscreen With Titanium Doixide (Tio2) Nano Particles: A societal Experiment, Original Paper, Netherlands.

[8] Nurma, 2013. Formulasi Dan Evaluasi Lulur Keraton Sumenep Menggunakan Beberapa Basis Krim. Thesis, Universitas Airlangga, Surabaya.

[9]Lowe J, 1998. Sunscreen Development, Evaluation, and Regulatory Aspect, Phoenix Arizona, P. 441 
[10]. Gennaro, 1990. Remington's Pharmaceutical Sciences 18th Edition, Mack Publishing Company, Pennsylvania.

[11]. Engelen L, De Wijk R.A, Van der Bilt A, Prinz J.F, Janssen A.M, Bosman F. "Relating Particle And Texture Perception", Phsiology and Behaviour 86, 2005, pp 111-117

[12]Rowe, R.C., Sheskey, P.J., Weller, P.J., 2003. "Handbook Of Pharmaceutical Excipients", Fourth edition, America : Pharmaceutical Press, pp. 568.

[13] Sahu Alakh N, Jha S B and Dubey S D, "Formulation \& evaluation of curcuminoid based Herbal face cream". Indo-Global Journal of Pharmaceutical Sciences, 2011.vol- 1: pp77-84.
[14]Hemapatil,Bbakkppa,2012. "The influence of culture on cosmetics consumer behavior" IOSR Journal of Business and Management (IOSRJBM) Volume 3, Issue 4(Sep,-Oct.2012), PP 41-47,

[15] Allam Krishna Vamshi, Kumar gannu Praveen, Colorants, "The cosmetics For The Pharmaceutical Dosage Forms", International Journal Of Pharmacy And Pharmaceutical Sciences ISSN 0975-1491 Vol.3 Suppl 2011. 